University of Rhode Island

DigitalCommons@URI

Civil \& Environmental Engineering Faculty

Publications

Civil \& Environmental Engineering

2019

\title{
Influence of Microencapsulated Phase Change Materials (PCMs) on the Chloride Ion Diffusivity of Concretes Exposed to Freeze- thaw Cycles: Insights from Multiscale Numerical Simulations
}

Sumeru Nayak

University of Rhode Island

Gideon A. Lyngdoh

Sumanta Das

University of Rhode Island, sumanta_das@uri.edu

Follow this and additional works at: https://digitalcommons.uri.edu/cve_facpubs

The University of Rhode Island Faculty have made this article openly available.

Please let us know how Open Access to this research benefits you.

This is a pre-publication author manuscript of the final, published article.

Terms of Use

This article is made available under the terms and conditions applicable towards Open Access

Policy Articles, as set forth in our Terms of Use.

Citation/Publisher Attribution

Nayak, S., Lyngdoh, G. A., \& Das, S. (2019). Influence of Microencapsulated Phase Change Materials (PCMs) on the Chloride Ion Diffusivity of Concretes Exposed to Freeze-thaw Cycles: Insights from Multiscale Numerical Simulations. Construction and Building Materials, 212, 317-328. doi: 10.1016/ j.conbuildmat.2019.04.003

Available at: https://doi.org/10.1016/j.conbuildmat.2019.04.003

This Article is brought to you for free and open access by the Civil \& Environmental Engineering at DigitalCommons@URI. It has been accepted for inclusion in Civil \& Environmental Engineering Faculty Publications by an authorized administrator of DigitalCommons@URI. For more information, please contact digitalcommonsgroup@uri.edu. 


\title{
Influence of Microencapsulated Phase Change Materials (PCMs) on the Chloride Ion Diffusivity of Concretes Exposed to Freeze-thaw Cycles: Insights from Multiscale Numerical Simulations
}

\author{
Sumeru Nayak, Graduate Student, Civil and Environmental Engineering, University of Rhode \\ Island, Kingston, RI 02881, United States \\ Gideon A. Lyngdoh, Graduate Student, Civil and Environmental Engineering, University of \\ Rhode Island, Kingston, RI 02881, United States \\ Sumanta Das, Assistant Professor, Civil and Environmental Engineering, University of Rhode \\ Island, Kingston, RI 02881, United States, Email: sumanta_das@uri.edu (corresponding author)
}

\begin{abstract}
Use of phase change materials (PCMs) to tailor the thermal performance of concretes by efficient energy storage and transmission has gained traction in recent years. This study incorporates microencapsulated PCMs as sand-replacement in concrete bridge decks and performs numerical simulation involving multiple interactive length scales to elucidate the influence of PCM-incorporation in concretes subjected to combined freeze-thaw and chloride ingress-induced deterioration. The simulations show significant increase in durability against combined freeze-thaw and chloride ingress-induced deterioration in concretes when microencapsulated PCMs are incorporated. In addition, a reliability-based probabilistic analysis shows significant increase in life expectancy of bridge decks with PCM-incorporation. The numerical approach presented here provides efficient means to develop design strategies to tune dosage and transition temperature of PCMs to maximize durability of concrete structures in regions that experience significant winter weather conditions.
\end{abstract}

Keywords: Phase Change Materials (PCMs), Microstructure; Finite element; Damage; Freeze-thaw; chloride ingress; durability 


\section{INTRODUCTION}

Application of thermal energy storage capacity of microencapsulated paraffinic phase change materials (PCMs) towards enhanced energy efficiency of structures has been an active area of research in construction materials [1-4]. The ability of PCMs to store and release heat has been shown to introduce a thermal inertia in structural concretes thereby enhancing performance [2,4-6]. Previous studies have shown the effectiveness of PCMs towards improving energy efficiency of buildings and indoor thermal comfort [69]. PCMs have also been successfully used to arrest thermal cracking in concrete pavements during early ages of hydration. [10-12]. The modularity of PCMs in terms of availability of wide range of transition temperatures warrants various beneficial applications in infrastructure materials $[1,13]$. PCMs have been proposed for application in concrete pavements and bridges for improved performance under freeze-thaw cycles [4,13]. A common method of removing ice and snow from the surface of pavements and bridges is application of deicing salts [4,13-17]. Such process is not only labor intensive but also a major source of dissolved chlorides in concrete that can cause catastrophic damage to the underlying structures. A combined degradation of the concrete occurs by the freeze-thaw induced cracks and chloride diffusion through those cracks which can cause reinforcement-corrosion [4,13,18-20]. An efficient alternative method can be the incorporation of PCMs in concrete $[1,4,21]$ which readily takes advantage of the high latent heat of PCMs that is released in freezing ambient conditions. A recent experimental study [4] corroborates the application of PCMs in concrete to reduce snow formation. The improved frost-resistance of such concretes has also been reported in another recent study [21]. Numerical studies involving one dimensional finite difference technique have also shown the effectiveness of PCMs in concrete subjected to freeze-thaw cycles $[10,13,21]$.

While previous studies report on effectiveness of PCMs towards improved frost-resistance, this paper focuses on evaluation of the influence of PCMs on the performance and life-expectancy of concrete bridge decks subjected to combined freeze-thaw cycles and chloride-ingress using multiscale numerical simulations. The input properties of the materials used for macro-scale finite element analysis are obtained from multi-scale numerical homogenization. The effective properties, thus obtained, are used to obtain the surface temperature profile of a concrete bridge deck for a given period of time under ambient temperature and incident solar radiation. The simulation approach efficiently integrates the influence of latent heat of PCMs. The surface temperatures enable prediction of freeze thaw cycles. The volumetric expansion of the freezing pore solution causes stiffness-loss while the applied deicing salts (to remove snow) inundate the surface with dissolved chlorides. To have a deeper insight into the material degradation and resulting accelerated chloride ingress, the heterogeneity of the concrete is encompassed in this study by a 
microstructure-guided analysis at the meso and micro scales. While continuum damage mechanics is used to quantify the progressive material degradation with freeze thaw cycles [22-25], Fick's law of diffusion [26-28] is used to capture the resulting accelerated chloride diffusion behavior in the degraded concrete. Thereafter, a first-order reliability-based probabilistic analysis predicts the influence of PCMs on the life expectancy of bridge decks. This study achieves an integration between the material microstructure and the macro-scale bridge deck structure to predict lives of such structures subjected to combined freeze-thaw and chloride ingress-induced deterioration. The numerical approach thus provides a tool to designers and engineers alike to provide efficient design strategies which can be tailored to build durable structures in varying environments. Furthermore, this approach will facilitate the development of freeze-thaw resistant concretes with conventional strength that can find numerous applications not only in bridge decks but also in any exposed concrete surfaces subjected to chloride environments and harsh freezing ambient temperatures.

\section{NUMERICAL SIMULATION OF FREEZE-THAW RESPONSE}

In order to elucidate the influence of PCMs on the freeze-thaw response of concrete, a multi-scale analysis is carried out here using continuum micromechanics. The following sub-sections perform multi-scale numerical homogenization for effective properties of concrete which are used as input for macro scale analysis of thermal response of concrete bridge deck under ambient conditions in Providence, RI, United States. The macroscopic thermal responses for both the concrete decks are further used to obtain freezethaw induced damage response as detailed later in this section. Schematic diagram, shown in Figure 1, elucidates the steps involved in the numerical simulation framework. Firstly, a numerical homogenization approach predicts the effective properties of the cementitious systems which are used as input to the thermal analysis of macro-scale bridge decks. The macro-scale analysis predicts the temperature distributions in the bridge deck under ambient weather conditions. The macro-scale thermal response, thus obtained, is used to characterize the freeze thaw-induced damage in the microstructure. The damaged microstructure is thereafter subjected to chloride diffusion to evaluate the durability. 

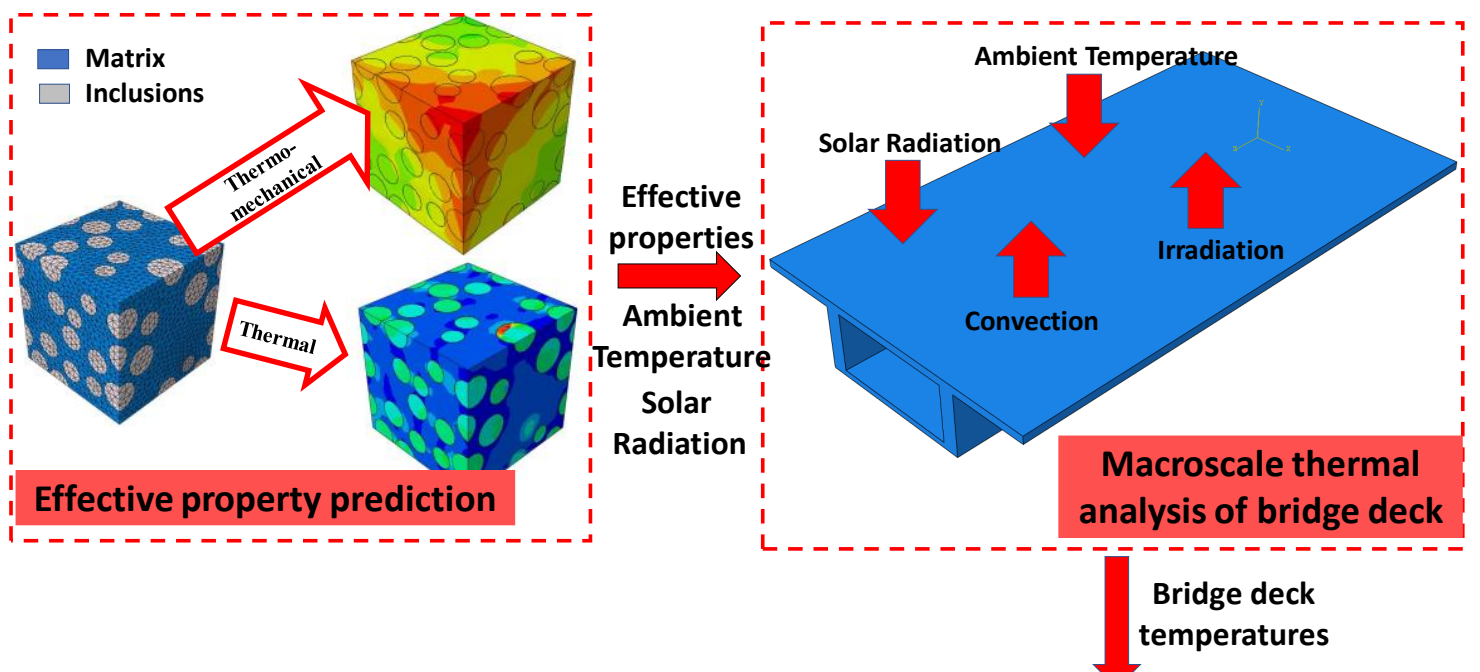

Bridge deck temperatures

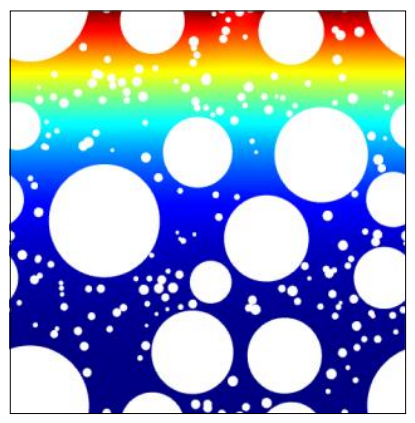

Chloride diffusion in damaged microstructure
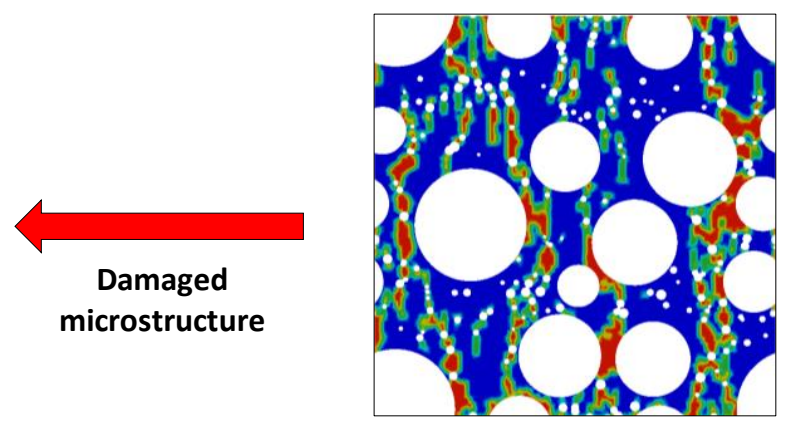

Freeze-thaw induced damage in microstructure

Figure 1. Schematic representation of the different interactive length scales involved in the analysis

\subsection{Prediction of effective properties}

A numerical simulation approach involving microstructure-guided effective property prediction is implemented in this section at multiple length scales. The numerical homogenization approach is schematically illustrated in Figure 2. The approach involves: (1) representative unit cell generation implementing the known microstructural features of the material, (2) application of periodic boundary conditions (PBCs) [29-32] and (3) implementation of a post-processing module that yields effective properties as explained in the forthcoming sub-sections. 


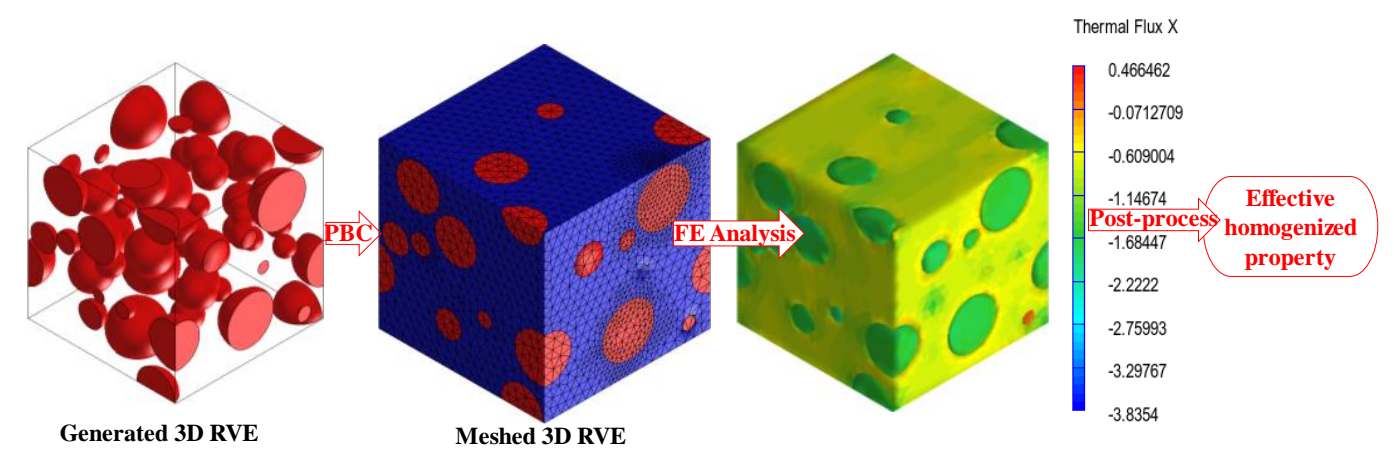

Figure 2. A schematic diagram showing the FE based numerical homogenization approach employed to obtain effective thermal responses

\subsubsection{Representative Unit cell generation and Boundary Conditions:}

The Lubachhevsky-Stillinger algorithm [33-36] is used here to generate the representative unit cell. In this algorithm, a hard contact model is employed that prohibits particle overlaps. The algorithm randomly distributes the desired inclusions inside a periodic bounding box with random initial velocities. Next, the radius of each particle grows as a function of time. The desired particle size distribution is obtained from the tailored growth rate. The forward Euler scheme is used to update the positions of the particles with a time step that is minimized with events of possible collisions between particles. Detailed formulations of the iterative process where particles change positions in the bounding box, collide and grow to achieve the desired volume fraction are mentioned elsewhere [37]. Periodic boundary conditions (PBC) [29-32] are applied to the generated unit cells. Such boundary conditions are computationally efficient and therefore suited for faster convergence in smaller analysis domains. [38]. For thermal analyses, the continuity of temperature/ heat flux is ensured by PBC across the neighboring unit cells boundaries. PBCs are detailed adequately in [39] and successful application of PBCs in heterogeneous composites towards effective property prediction has been demonstrated in [40]. A Python script implements the microstructural formulations to generate a unit cell and mesh it. Thereafter, the script applies PBC to generate periodically bounded meshed microstructure that can be imported to ABAQUS ${ }^{\mathrm{TM}}$ solver for FE analysis.

The numerical homogenization procedure involves generation of periodically bounded unit cells at each length scale with intrinsic material properties assigned to each component phase. At each length scale, the unit cell is subjected to a FE analysis and the response to a unit temperature gradient leads to prediction of effective properties. This paper considers two different concrete mixtures: (i) control concrete containing $30 \%$ fine aggregates and $40 \%$ coarse aggregates; (ii) concrete containing 20\% PCM as sand-replacement (24\% fine aggregates, 6\% PCMs and 40\% coarse aggregates). The paraffinic PCMs are considered to undergo a phase transition at $5.1^{\circ} \mathrm{C}$. This phase transition temperature has been chosen based on commercial 
availability. For the control mixture, the effective properties are calculated from a three-step homogenization approach. In the first step voids are homogenized with hardened cement paste (HCP) matrix. The homogenized property is assigned as property of matrix in the mortar scale (step-II) where sand particles are embedded in the matrix. Finally, the coarse aggregates are numerically homogenized with the mortar matrix, obtained from step-II, to yield the effective properties of concrete. A similar homogenization procedure is followed for PCM-incorporated concrete where the PCMs are dispersed in the HCP matrix along with the voids in Step-I followed by similar homogenization steps (steps II and III) as explained earlier for control concrete. The median particle sizes $\left(d_{50}\right)$ for PCMs, voids, sand and coarse aggregates are $7 \mu \mathrm{m}, 10 \mu \mathrm{m}, 600 \mu \mathrm{m}$ and $13.75 \mathrm{~mm}$ respectively[23,39,41,42]. Sizes of the RVEs adopted for the three length scales are $0.035 \mathrm{~mm}$ (Step-I), $12.75 \mathrm{~mm}$ (step-II) and $69.375 \mathrm{~mm}$ (step-III) respectively, obtained based on a sensitivity study. The numerical homogenization procedure is explained in detail in our previous publications $[38,39]$.

\subsubsection{Effective property computation}

The RVEs obtained at each length scale are subjected to thermal FE analysis. The FE analysis proceeds with C3D8R elements under a unit temperature gradient. A MATLAB $\odot$ script extracts the volume averaged responses to obtain effective properties. Effective thermal conductivity $\lambda_{e f f}$ is obtained from the volume averaged heat flux as per Equation 1 [39].

$$
\lambda_{e f f}=\bar{q}^{e}\left(\frac{L}{T_{L}-T_{0}}\right)
$$

Where the volume-averaged heat flux for all the elements in the unit cell with edge length $L$ is denoted by $\bar{q}^{e}$; and the temperature difference imposed across opposite faces is denoted by $\left(T_{L}-T_{0}\right)$. The reaction heat flux is volume averaged for all elements in the unit cell and its ratio with the imposed temperature difference is obtained which yields the effective volumetric heat capacity $\left(\rho C_{p}\right)_{\text {eff }}$ [43]. However, the incorporated PCMs undergo a phase change at the transition temperature which necessitates the incorporation of the corresponding latent heat in calculation of effective volumetric heat capacity for PCM incorporated concretes. During phase-transition at the transition temperature, the released latent heat is added to the effective volumetric heat capacity $\left(\left(\rho C_{p}\right)_{e f f, s}\right)$ as shown in Equation 2 [5] to obtain effective volumetric heat capacity $\left(\left(\rho C_{p}\right)_{e f f, t}\right)$. The PCMs are considered to be in the solid state for simplicity $[5,13]$.

$$
\left(\rho C_{p}\right)_{e f f, t}=\left(\rho C_{p}\right)_{e f f, s}+\phi_{c} \frac{\rho_{c} h_{s f}}{\Delta T_{p c}}
$$


where $\phi_{c}$ is the PCM volume fraction; $\rho_{c}$ is the PCM density and $h_{s f}$ is the latent heat of fusion and $\Delta T_{p c}$ is the temperature window of phase transformation. The value of $\Delta T_{p c}$ is assumed to be $1^{\circ} \mathrm{C}$ [5]. For this study, the PCM has an absolute volume fraction of $6 \%$ in concrete, latent heat of fusion $150 \mathrm{~kJ} / \mathrm{kg}$ and density of $300 \mathrm{~kg} / \mathrm{m}^{3}[4,13,44,45]$. Table 1 shows the intrinsic thermal conductivities $(\lambda)$ [39] and specific heat capacities (C)[5] for each phase of both the concretes.

Table 1. Intrinsic thermal properties for PCM, Sand (FS), coarse aggregate (CA) and hardened cement paste (HCP) [39] [5]

\begin{tabular}{|c|c|c|}
\hline Phases & $\lambda(\mathrm{W} / \mathrm{m} \mathrm{K})$ & $\mathrm{C}(\mathrm{kJ} / \mathrm{kg} \mathrm{K})$ \\
\hline PCM & 0.15 & 2.6 \\
\hline Sand & 2.8 & 1.15 \\
\hline HCP & 0.75 & 0.75 \\
\hline CA & 2.3 & 0.79 \\
\hline
\end{tabular}

The effective thermal conductivities $(\lambda)$ for both control and PCM-incorporated concretes, obtained from the aforementioned framework, are $1.4 \mathrm{~W} / \mathrm{m} \mathrm{K}$ and $1.78 \mathrm{~W} / \mathrm{m} \mathrm{K}$ for the control and PCM incorporated concretes respectively. The corresponding effective volumetric heat capacities $\left(\rho C_{p}\right)_{e f f, s}$ for the control and PCM incorporated concretes are $0.88 \mathrm{~kJ} / \mathrm{kg} \mathrm{K}$ and $0.928 \mathrm{~kJ} / \mathrm{kg} \mathrm{K}$ respectively. The obtained homogenized effective properties correlate well with the ones reported in the literature for control concrete $[5,13]$ and for PCM incorporated concrete [5,39]. These effective properties are used in the forthcoming section to evaluate thermal response of a concrete bridge deck (macro-scale).

\subsection{Upscaling to macro-scale freeze-thaw response}

A macro-scale FE analysis is presented in this section to evaluate thermal responses of the control concrete as well as PCM-incorporated concrete. To illustrate the influence of PCM incorporation, the temperature profiles at the surface of the corresponding decks are obtained. The macroscale thermal analysis is performed under ambient weather conditions in Providence, Rhode Island, United States.

\subsubsection{Bridge Deck model}

A commercial FE software ABAQUS ${ }^{\mathrm{TM}}$ is used to model the three dimensional bridge deck with a box girder section as shown in Figure 3. The length, breadth and thickness of the bridge deck are considered to be $17.09 \mathrm{~m}, 10 \mathrm{~m}$ and $240 \mathrm{~mm}$ respectively. Similar dimensions for box girder bridges are adopted in $[46,47]$ 




Figure 3. 3D geometry of a box girder bridge deck section showing the boundary conditions and the ambient thermal interactions

Figure 3 also shows the thermal interactions of the structure with the ambience thereby forming the thermal boundary conditions. The weather data of Providence, Rhode Island is obtained from [48]. It includes hourly atmospheric temperature data and global horizontal irradiance (GHI) data. GHI embodies the short wave radiation received on unit horizontal ground surface which is composed of diffused short wave radiations and normal incident solar radiation. The absorptivity $\left(\beta_{S}\right)$ of concrete is considered 0.59 [49] which is multiplied with the daily maximum GHI $\left(q_{s}\right)$ to obtain the incident surface heat flux. This is applied as a thermal load applied to the heating step during the day in the simulation. The heat transfer interactions are determined by the hourly ambient temperature $\left(T_{0}\right)$. The difference between the deck surface temperature and ambient temperature, $\left[\left(T(0, t)-\left(T_{0}\right)\right]\right.$ is multiplied with the surface convection coefficient $\left(h_{0}\right)$ to yield the convective interaction [50,51]. The value of $h_{0}$ is considered to be $26 \mathrm{~W} / \mathrm{m}^{2} \mathrm{~K}$ for the interface of air and concrete for low wind speeds [52], which is incorporated in the model as a surface film coefficient. Convection occurs in the air inside the box and between the deck surface and the atmosphere. The radiative heat transfer is obtained by multiplying the Stefan-Boltzmann radiation constant $(\sigma)$, the surface emissivity of concrete $(\varepsilon)$ and the difference of the fourth powers of ambient temperature $\left(T_{0}\right)$ and deck surface temperature $T(0, t)[51]$. The values of $\sigma$ and $\varepsilon$ are considered to be $5.6697 \times 10^{-11}$ $\mathrm{kW} / \mathrm{m}^{2} \mathrm{~K}^{4}$ and 0.92 respectively [51]. Surface radiation interaction is defined between the deck surface and the atmosphere (ambient temperature of $T_{0}$ ). The latent heat of the PCM incorporated concrete is defined as a material property that captures the change in internal energy during phase change in the phase transformation temperature window $\left(\Delta T_{p c}=1^{\circ} \mathrm{C}[5]\right)$. The analysis is carried out with a non-linear 
transient heat analysis step In the PCM incorporated concrete deck, the latent heat of $150 \mathrm{~kJ} / \mathrm{kg}\left(h_{s f}\right)$ is released by the PCMs at $5.1^{\circ} \mathrm{C}\left(T_{p c}\right)$; which when added to the volumetric heat capacity (see Equation 2 ) captures the complete change in internal energy.

\subsubsection{Macroscale thermal response}

The weather data is fed into the ABAQUS ${ }^{\mathrm{TM}}$ model by a MATLAB $\odot$ script where the heat transfer interactions by conduction, radiation and convection are defined. Hexahedral DC3D8 elements are used to carry out the transient heat transfer analysis in ABAQUSTM solver. A mesh convergence study was performed and a mesh containing 1386 nodes and 880 elements yielded converged solution. A post processor subroutine operates on the output file and extracts the deck surface temperature data for January,2018 in Providence, RI, as reported in Figure 4. As shown in Figure 4, the solar radiation causes the peak surface temperature to rise beyond the ambient temperature, as noted elsewhere $[10,13]$. However, the amplitude of temperature variation is significantly reduced for PCM incorporated concrete. The heat released at its transition temperature introduces a thermal inertia that results in higher deck temperatures compared to control concrete. Under an ambient temperature of $-19{ }^{\circ} \mathrm{C}$ (lowest minimum ambient temperature for the month of January 2018) bride deck surface temperatures for control and PCM incorporated concrete are $-16.25^{\circ} \mathrm{C}$ and $-14.75^{\circ} \mathrm{C}$ respectively.

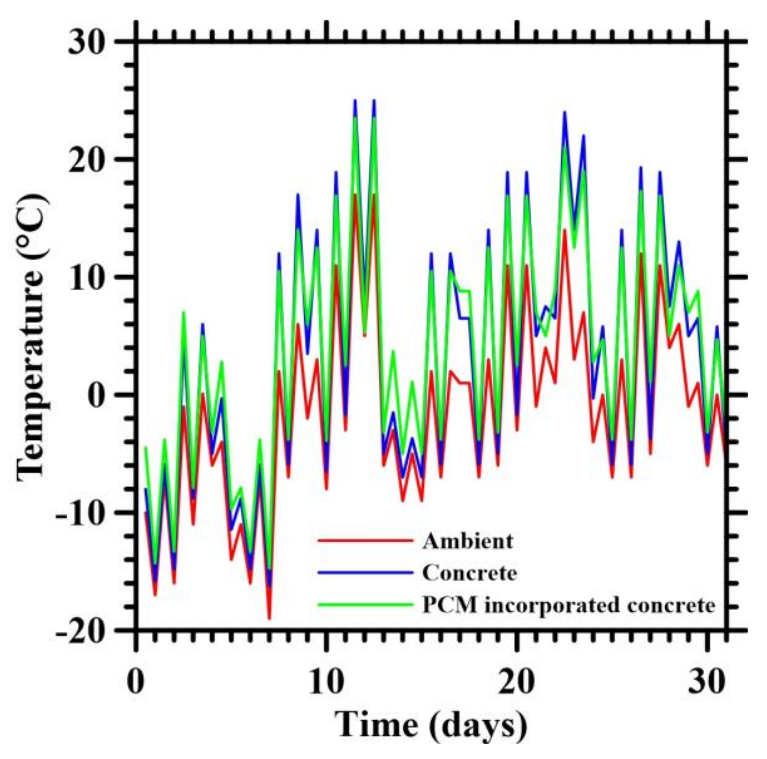

Figure 4. Temperature profile at the top surface of the bridge decks under imposed ambient temperatures for January 2018 in Providence, RI

The surface temperature profiles depict the effectiveness of PCMs in reducing the number of freeze thaw cycles since PCM-incorporated concrete decks demonstrate higher surface temperatures even under extreme low ambient temperatures. Consequently, considering a freezing temperature of $-5.5^{\circ} \mathrm{C}$ and 
thawing temperature of $0^{\circ} \mathrm{C}$ for water filled pores in concrete [13,53], the number of freeze thaw cycles are computed to be 3 for PCM modified concrete and 10 for the control concrete during January 2018. The temperature profiles, thus obtained, are employed in the forthcoming section to quantify the beneficial impact of PCMs on the freeze-thaw-induced damage response in concrete which is further used later in this paper towards simulation of chloride ion diffusion in concrete, damaged due to freeze thaw cycles for a detailed insight.

\subsection{Damage due to freeze-thaw cycles}

The damage response analysis is performed involving two length scales as shown in Figure 5. First, a fourphase system is modelled with sand inclusions, interfacial transition zone (ITZ), voids and HCP matrix (see Figure 5 (a-1)) for control mortar. PCM-incorporated system contains an additional inclusion phase of PCMs as sand-replacement (see Figure 5 (b-1)). The thickness of ITZ is assumed to be $20 \mu m$ [54-56]. The progressive damage in the matrix is implemented here using a user-defined subroutine in ABAQUS ${ }^{\mathrm{TM}}$. The effective degraded Young's modulus of the mortars is computed by a post-processing subroutine, coded in MATLAB $^{\mathrm{TM}}$ and used as matrix-property in the meso-scale (see Figures 5 (a-2) and (b-2)) where coarse aggregates are dispersed in the mortar matrix. Numerical homogenization for Young's modulus is performed to obtain degraded Young's modulus of the concretes as explained later in this paper.

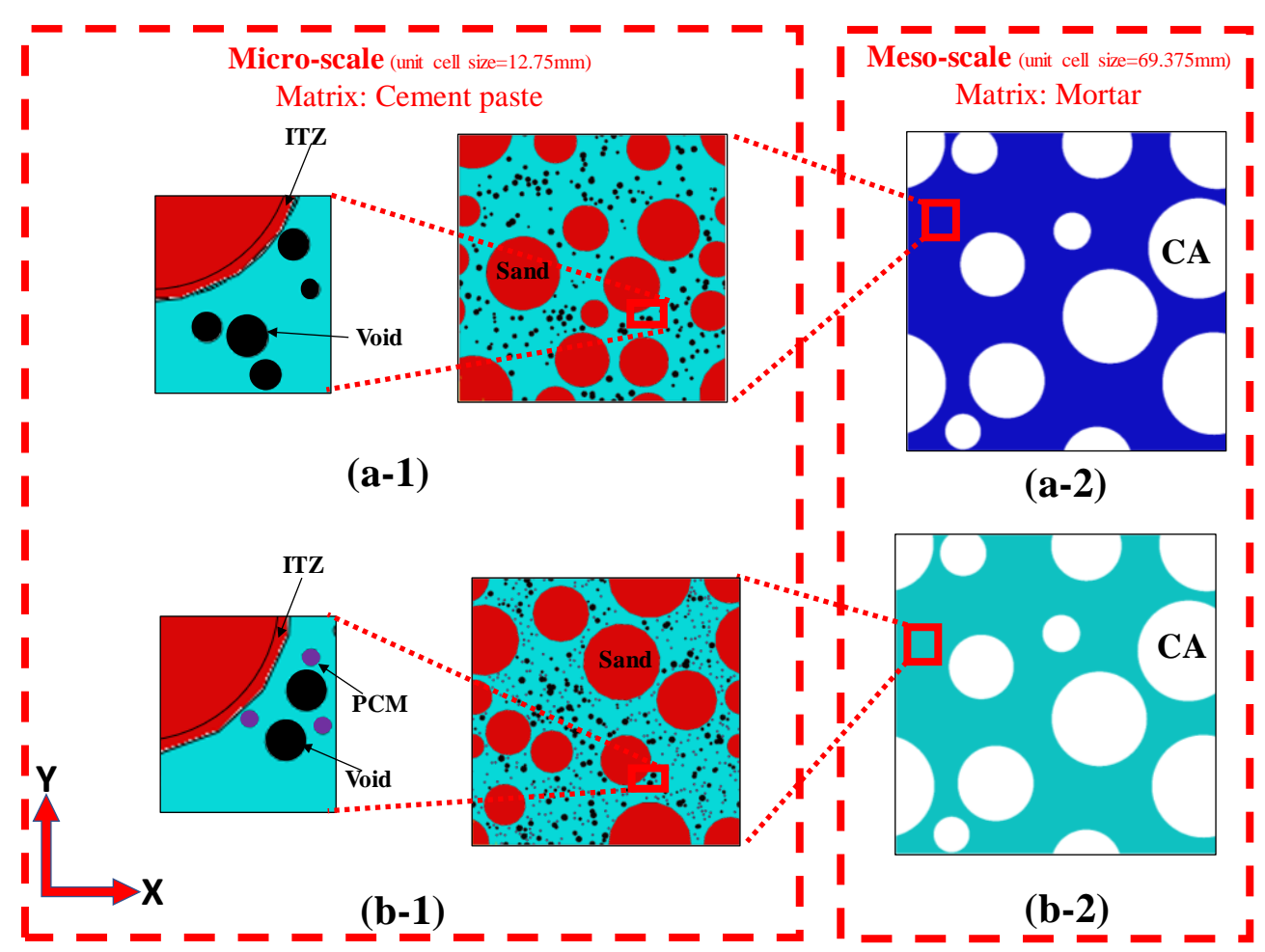

Figure 5. The generated unit cells for: (a-1) mortar containing $10 \%$ voids, $40 \%$ hardened cement paste (HCP) and 50\% sand with; (a-2) Control concrete containing 40\% coarse aggregate (CA) and 60\% mortar matrix; (b-1) PCM-incorporated mortar containing 10\% voids, $10 \%$ PCM, 40\% HCP and 40\% sand by 
volume, (b-2) PCM-incorporated concrete containing 40\% coarse aggregate and $60 \%$ PCM-modified mortar

\subsubsection{Numerical Simulation of isotropic damage in matrix induced by freeze-thaw cycles}

The volume expansion of the water filled voids in the cement paste matrix is implemented using a user defined subroutine for ABAQUS ${ }^{\mathrm{TM}}$ solver. The analysis approach adopted herein imports the bridge deck surface temperatures (Figure 4) and implements volumetric expansion in the pores for temperatures below $-5.5^{\circ} \mathrm{C}[13,53]$. An artificial coefficient of thermal expansion of the pores is implemented so as to obtain a 9\% volumetric expansion in the pores due to freezing. Similar approach was successfully adopted in [51]. As the temperature rises above $0^{\circ} \mathrm{C}$, the volumetric expansion is released.[57]. The ensuing mechanical damage is captured using continuum damage laws described later. The intrinsic Young's modulus of HCP, sand, ITZ and coarse aggregates, adopted from literature [23,41,58,59] are $22.4 \mathrm{GPa}, 70 \mathrm{GPa}, 4.45 \mathrm{GPa}$ and 74.5 GPa respectively. A Poisson's ratio of 0.2 is assigned to all the component phases except PCMs. The Poisson's ratio for PCMs is considered as 0.4 [41]. The median sizes of voids, PCM, sand and aggregates are adopted as $10 \mu \mathrm{m}, 7 \mu \mathrm{m}, 600 \mu \mathrm{m}$ and $13.75 \mathrm{~mm}$ respectively [23,39,41,42]. The ITZ is considered $20 \mu \mathrm{m}$ thick [54-56]. A post-processor subroutine computes the constitutive response of the degraded material and compiles the degraded Young's modulus with varying freeze-thaw cycles.

This approach bridges the macro scale response of the concrete bridge deck to the micro and mesoscales by implementing volumetric expansion of water filled voids once the macro scale surface temperature drops below $-5.5^{\circ} \mathrm{C}$. In the analysis framework, the resultant hydraulic pressure in the pores due the strains causes an average stress that applies to the porous matrix, here the cement paste [60]. The stiffness degradation in

the matrix results from a cyclic expansion during freezing and a contraction during thawing, with $\frac{\Delta V}{V}$ being 0.09 . The continuum damage implemented in the matrix is characterized by a damage variable $D$ that has a value between 0 and 1 which signify undamaged and completely damaged states respectively. Assuming isotropic stiffness degradation, $D$ is defined as per Equation 3 [22-25,61].

$$
\sigma=(1-D) C: \varepsilon
$$

Where $\sigma$ denotes the effective stress tensor, $\varepsilon$ is the strain tensor and $C$ denotes the elasticity tensor. The overall damage $D$ is composed of its tensile $\left(D_{t}\right)$ and compressive $\left(D_{c}\right)$ parts (see Equation $4[23,24]$

$$
D=\alpha_{t} D_{t}+\alpha_{c} D_{c}
$$

A non-local equivalent strain $\tilde{\varepsilon}$,defined in Equation 5 [22,23], is used to obtain $D_{t}$ and $D_{c}$.

$$
\tilde{\varepsilon}=\sqrt{\sum_{i}<\varepsilon_{i}>_{+}^{2}}
$$


Where $\left\langle\varepsilon_{i}\right\rangle_{+}$is the positive part of the principal strain. The tensile and compressive components of damage $\left(D_{t}\right.$ and $\left.D_{c}\right)$ evolve as a function of $\tilde{\varepsilon}$ as per the Equation $6[22-25,61]$.

$$
D_{t, c}(\tilde{\varepsilon})=1-\frac{\varepsilon_{D_{0}}\left(1-A_{t, c}\right)}{\tilde{\varepsilon}}-\frac{A_{t, c}}{\exp \left[B_{t, c}\left(\tilde{\varepsilon}-\varepsilon_{D_{0}}\right)\right]}
$$

Where $\varepsilon_{D_{0}}$ is damage initiation threshold. Experimentally obtained uniaxial tensile and compressive curves can characterize the values of the parameters $A_{t, c}$ and $B_{t, c}$. The values of the parameters $A_{t}$ and $B_{t}$ for cement paste are 1 and $10^{4}$ respectively while those of $A_{c}$ and $B_{c}$ are 1.2 and $1.5 \times 10^{3}$ respectively while $\varepsilon_{D_{0}}=0.0001[62]$.

\subsubsection{Frost-damage response}

The progressive damage in the paste matrix is shown in Figure 6 for the control and PCM incorporated cases for January $20^{\text {th }}$ (See Figures $6(\mathrm{a}-2)$ \& (b-2)) and January $31^{\text {st }}$ (See Figures 6 (a-3) \& (b-3)) respectively for the year 2018 in Providence, Rhode Island. It should be noted here that the damage response presented in this section for a comparative performance evaluation corresponds to the top surface of the bridge deck. Overall, the damage observed in control mortar is significantly higher than the PCMincorporated mortar which demonstrates the durability benefit of PCM-incorporation. A significantly higher mechanical degradation, especially at the surface of a structure can be detrimental to its usability and mechanical integrity resulting from rebar corrosion in $\mathrm{RC}$ structures.

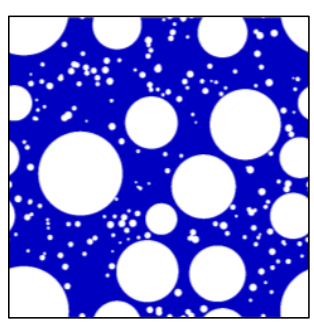

(a-1)

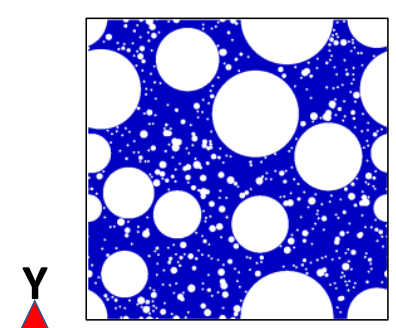

(b-1)



$(\mathbf{a}-2)$



(b-2)

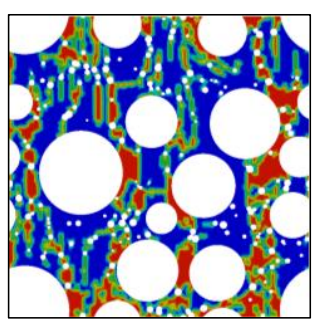

(a-3)

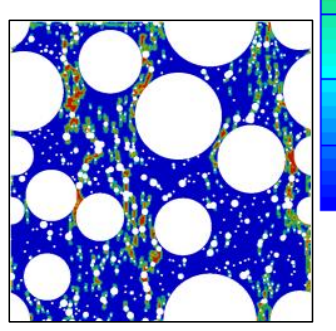

(b-3)

\section{Damage}

0.9

0.7875

0.675

0.5625

0.45

0.3375

0.225

0.1125

0

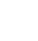

0

Figure 6. Frost-induced damage for: (a) control mortar: (a-1) initial geometry; (a-2) Day 20; (a-3) Day 31, (b) PCM-incorporated mortar: (b-1) initial geometry; (b-2) Day 20; (b-3) Day 31 
The degraded mechanical properties obtained in the micro-scale analysis is used as an input matrix property in the meso-scale to obtain a homogenized response of the concrete scale for both control and PCMincorporated cases.

The normalized degraded modulus of elasticity (with respect to initial Young's modulus) obtained for the control concrete are plotted along with experimental results obtained from [63] in Figure 7. The values show close correlation thereby validating the framework of frost-induced damage.

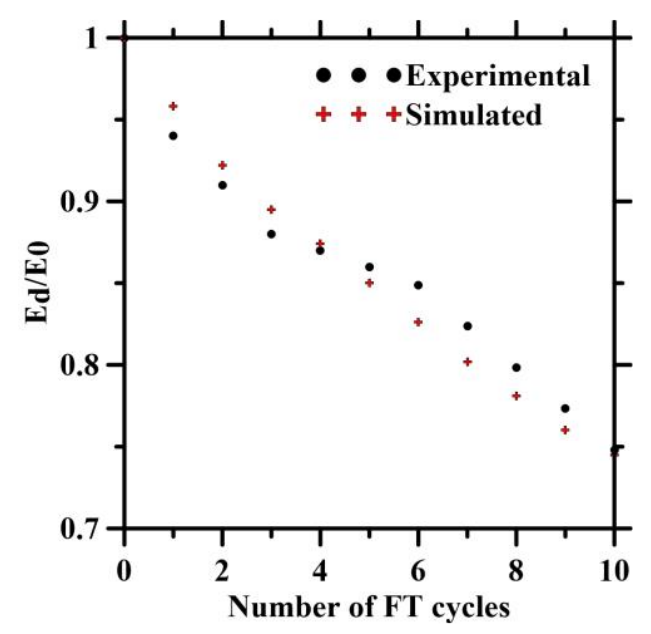

Figure 7. Comparison of simulated damage response with experimental results adopted from [63]

\subsection{Impact of PCM-incorporation on the freeze-thaw induced damage in concrete}

The validated framework is used to quantify the damage response induced by freeze-thaw cycles for both the PCM-incorporated and control mortars as well as concretes. The relative degradation is captured by the ratio of degraded Young's modulus $\left(\mathrm{E}_{\mathrm{d}}\right)$ to the initial Young's modulus $\left(\mathrm{E}_{0}\right)$. Figure 8(a) shows the relative performance of the PCM-incorporated mortar with respect to the control mortar for January 2018 in Providence, RI. A significant reduction in stiffness-degradation is observed for PCM-incorporated case implying superior freeze-thaw-durability of PCM-incorporated mortars due to its ability to stay relatively warm even in freezing ambient conditions. Figure 8(b) shows the performance of control and PCMincorporated concretes. The freeze-thaw-durability efficiency of PCMs reduces in concrete when compared to mortars for the obvious dilution effect. However, a significant $18 \%$ reduction in the stiffness-degradation is still observed with PCM-incorporation in concrete highlighting the effectiveness of PCMs in improving freeze-thaw-durability of concrete. A major consequence of a degraded surface of a bridge deck is diffusion of water and dissolved ions in the concrete [64,65]. This can lead to corrosion of embedded steel reinforcement which is very pronounced in areas exposed to salts in the environment [66]. In order to study the beneficial impact of PCM-incorporation on the life of a bridge deck structure, it is necessary to obtain a comparative picture of the diffusion fronts of dissolved ions over a fixed duration. The forthcoming 
section describes a fluid diffusion model that computes a comparative assessment of the chloride resistance of both control and PCM-incorporated mortars subjected to freeze-thaw-induced damage.
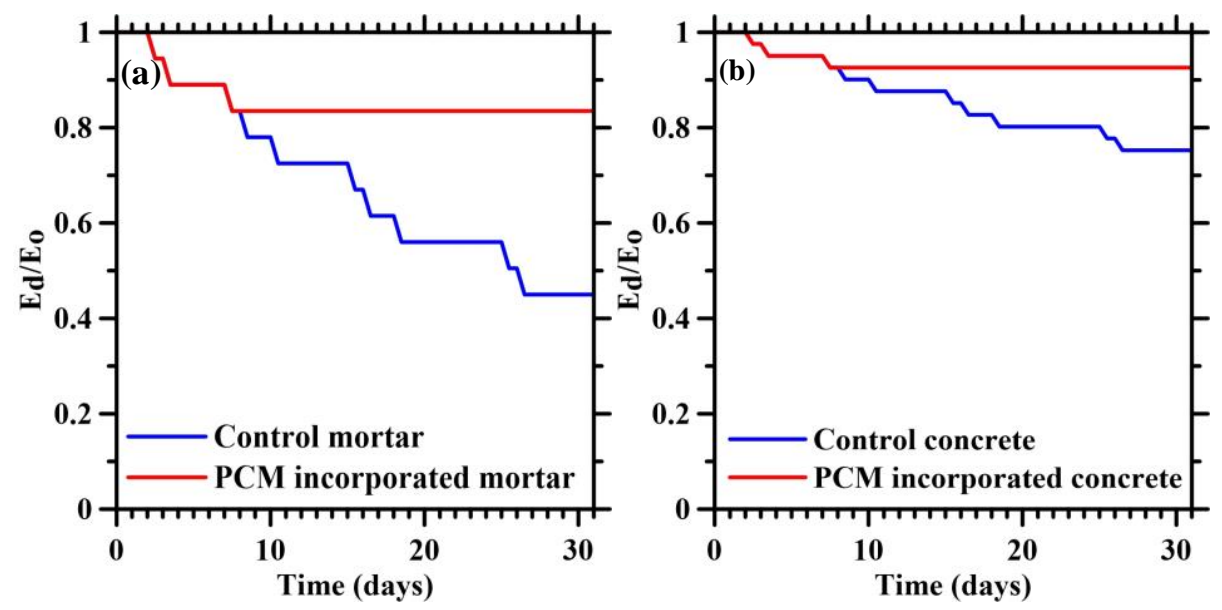

Figure 8. Relative ratios of degraded elastic modulus $\left(E_{d}\right)$ to initial modulus $\left(E_{0}\right)$ for January 2018 for: (a) mortars and (b) concretes

\section{NUMERICAL SIMULATION OF IONIC DIFFUSION IN FREEZE-THAW-DAMAGED CONCRETES}

This section aims to depict the accelerated chloride diffusion in degraded concrete under freeze-thaw action. The transport behavior of chlorides is significantly affected by the void structure generated owing to freezethaw damage. Thus a coupled approach is adopted here that accounts for the influence of freeze-thawinduced damage on the chloride ion diffusion at multiple length scales. Therefore, a better insight can be gained into the influence of PCMs on the life expectancy of structures from a detailed analysis of its microscale behavior. Figure 9 illustrates the coupled approach where the generated RVE is subjected to freeze-thaw-induced volume expansion and contraction resulting in mechanical damage. A remeshing module improves the mesh of the damaged/deformed structure and exports the damaged microstructure as a starting meshed geometry for the diffusion model. The damaged elements therein behave as cracks in the diffusion model which is subjected to a chloride concentration gradient. A post-processing module computes the volume averaged effective diffusion coefficient $D_{e}$ for each damage state. 

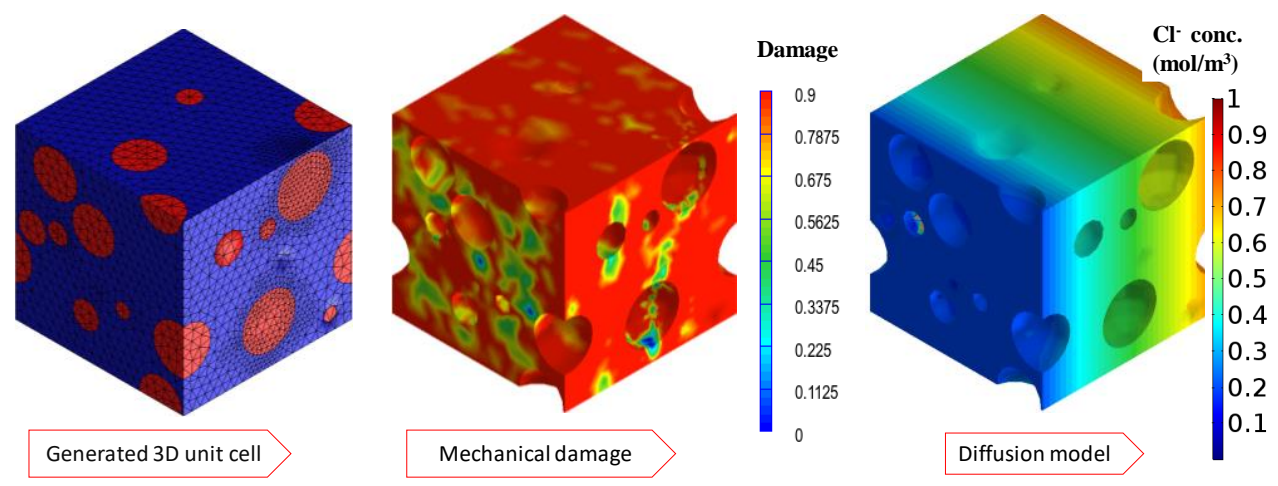

Figure 9. A schematic representation of the coupled freeze-thaw damage-diffusion approach to study chloride diffusion in frost-deteriorated microstructure

\subsection{Chloride ion diffusion in Concrete exposed to freeze-thaw cycle}

Application of deicing salts (to melt snow and ice) on bridge decks and pavements results in presence of aqueous salt solution on the surface and it serves as a major source of dissolved chlorides which diffuse into the concrete structure thereby accelerating the damage. The chloride diffusivity of highly heterogeneous porous materials like cementitious composites strongly depends on the void-distribution in the microstructure and it is characterized by the diffusion coefficient which can be correlated with the properties of cement paste matrix and ITZ assuming impermeable aggregates [28]. Freeze-thaw cycleinduced damage causes an increased porosity in the microstructure that in turn accelerates chloride diffusion. Fick's law expresses the flux of chlorides $J$ as shown in Equation 7 [28].

$$
J=-D_{k} \nabla C
$$

Where the Laplace differential operator $\nabla$ operates on $C$ (concentration of chlorides), and the diffusion coefficient of $k^{\text {th }}$ phase (here: aggregate, ITZ and HCP) is denoted by $D_{k}$. A necessary condition for mass conservation is given as [28]

$$
\frac{\partial C}{\partial t}=-\nabla J
$$

Where $t$ is the diffusion time. Equation 8 implies no accumulation of chlorides which has been reported to be the case with deicing salt application [20]. Combining the Equations 7 and 8, the following equation is obtained.

$$
\frac{\partial C}{\partial t}=D_{k} \nabla^{2} C
$$

Equation 9 relates the contribution of individual components in a heterogeneous material to chloride diffusion with time. Thus, the whole model establishes a quantitative relationship between porosity and chloride diffusion by a nonlinear diffusion coefficient assigned to each phase of a random microstructure. 
Moreover, the coupled approach with frost-induced damage and chloride diffusion (see Figure 9) ensures an interactive framework of quantitative characterization of durability. The interaction is achieved by proportionally increasing the diffusion coefficient of the damaged elements in tandem with the progress of mechanical damage. The proportional increase of intrinsic diffusion coefficient of the damaged elements with the progressive damage $D$ is defined in Equation 10.

$$
D_{d e l}=D_{c r} \cdot D
$$

Where $D_{d e l}$ is the diffusion coefficient of the damaged element and $D_{c r}$ is the diffusion coefficient of a crack (implying damage state 1 ) and $D$ is the progressive damage variable. Such proportional intrinsic properties has been successfully assigned to degraded materials for electromechanical [37] and thermomechanical [67] analysis.

\subsubsection{Model specifications and FE implementation}

The deformed configuration (Figure 6) obtained from the mechanical FE analysis is re-meshed ensuring a good quality of elements (aspect ratio $\leq 3$ ). Thereafter, the re-meshed geometry is used for the diffusion FE analysis. The microstructure generated in Section 2.3 has circular aggregates which is sufficient for analysis since shape of aggregates has been shown to not impact diffusion $[68,69]$. The width of ITZ is $20 \mu m$ as mentioned earlier. A FE analysis of diffusion is carried out in ABAQUS ${ }^{\text {TM }}$ solver using DCC2D4 elements. A differential concentration of $0.1 \mathrm{~mol} / \mathrm{m}^{3}$ is applied across the faces of the unit cell perpendicular to $\mathrm{Y}$ direction while the faces along $X$ are impermeable. Application of deicing salts leads to a surface chloride concentration of around $3.5 \mathrm{~kg} / \mathrm{m}^{3}$ [20] which is $0.1 \mathrm{~mol} / \mathrm{m}^{3}$ as adopted in the paper. The initial condition of the model has a zero concentration gradient across the faces along $\mathrm{x}$ and $\mathrm{y}$ axis. The diffusion coefficient of HCP matrix $D_{c p}$ is taken to be $1.2 \times 10^{-12} \mathrm{~m}^{2} / \mathrm{s}$ while that of aggregates is zero [70]. Since ITZ is porous, it has a higher diffusion coefficient than the matrix paste. In this study, the diffusion coefficient of ITZ is considered thirty times that of HCP as reported in [26]. The diffusion model, adopted here, assumes isothermal conditions. With the progress of freeze-thaw-induced isotropic damage, the value of diffusion coefficient for completely damaged elements $(D=1)$ is assumed to reach a realistically possible high value implying that the chloride ions can readily diffuse through such elements. A sufficiently high value of $D_{c r}=50,000$ times the $D_{c p}$ is adopted for the damaged matrix elements towards that end [26]. A post processing module computes the volume averaged chloride surface concentration with time from ABAQUS ${ }^{\text {TM }}$ solver to yield the apparent diffusion coefficient. 


\subsubsection{Accelerated chloride diffusion in frost-damaged microstructures}

Figure 10 shows the chloride ingress with the progress of freeze-thaw induced damage for control mortar (Figure 10(a)) and PCM-incorporated mortar (Figure 10(b)). In both the cases, the chloride ingress progresses with time which is accelerated due to frost induced damage. While Figures 10(a-1) and 10(b-1) show the initial states for control and PCM-incorporated mortars respectively where there is no chloride ingress, the Figures 10(a-2) and 10(b-2) correspond to first 20 days of exposure in January 2018. Figures 10(a-3) and (b-3) correspond to 31 days of exposure for control and PCM modified concrete respectively. Overall, the extent of penetration and the rate of chloride diffusion is significantly reduced when PCMs are incorporated establishing the effectiveness of PCMs to improve the durability of mortars. The effective diffusion coefficient obtained at the mortar scale is used as a matrix input property in the concrete scale. A numerical homogenization yields the effective diffusion coefficient in the concrete scale where the impermeable coarse aggregates are dispersed in the mortar matrix. Implication of these results on the expected life of structures is explored in detail later in this paper.

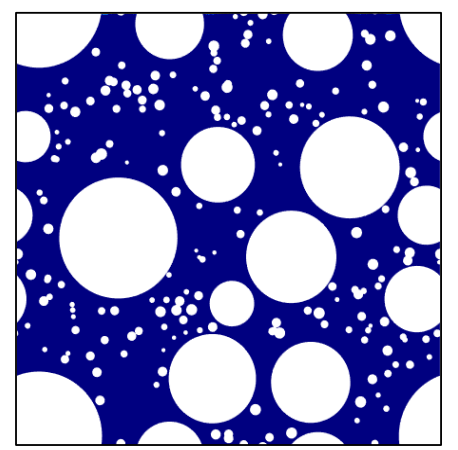

(a-1)

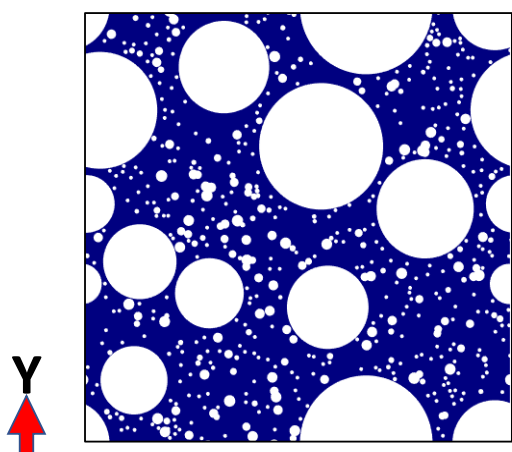

(b-1)

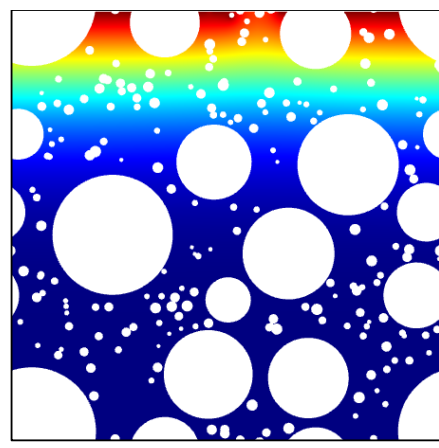

(a-2)

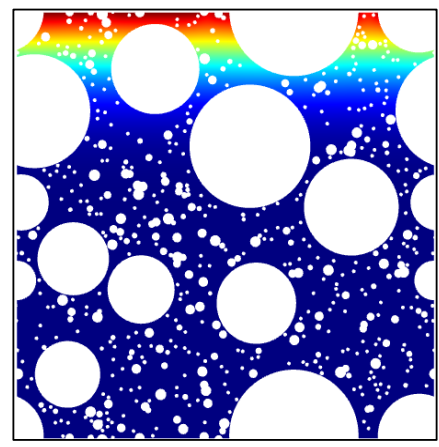

(b-2)

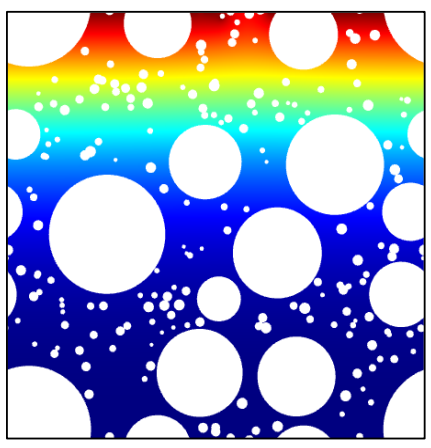

(a-3)

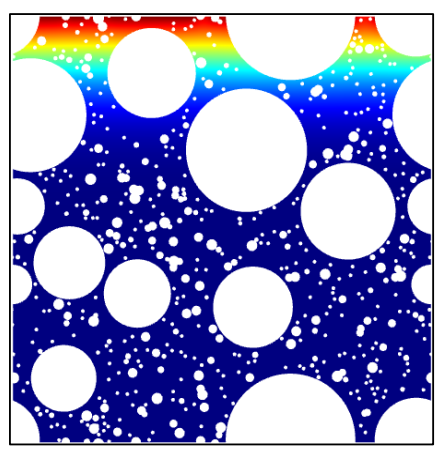

(b-3)
$\mathrm{Cl}^{-}$conc. (x $0.1 \mathrm{~mol} / \mathrm{m}^{3}$ x $3.5 \mathrm{~kg} / \mathrm{m}^{3}$ ) 1 0.9 0.8 0.7 0.6 0.5 0.4 0.3 0.2 0.1

Figure 10. Frost damage-induced chloride concentration distribution for: (a) control mortar: (a-1) initial geometry; (a-2) Day 20; (a-3) Day 31, (b) PCM-incorporated mortar: (b-1) initial geometry; (b-2) Day 20; (b-3) Day 31 
The accelerated diffusion behavior obtained for the control concrete is expressed as a ratio of degraded diffusion coefficient $\left(D_{e}\right)$ to the initial diffusion coefficient $D_{0}$ and is validated with experimental results [27] as shown in Figure 11. The values show close correlation thereby validating the framework of chloride diffusion in frost-damaged concrete.

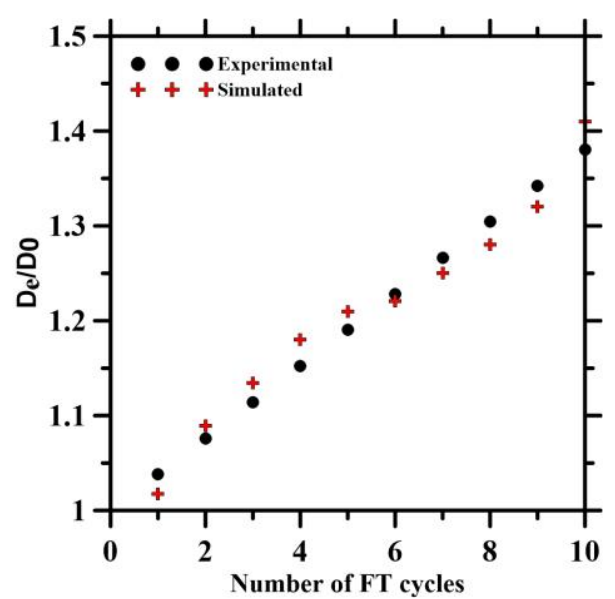

Figure 11. Validation of accelerated diffusion analysis results with experimental results adopted from [27]

\subsection{Influence of PCMs on chloride ion diffusivity of freeze-thaw-exposed concrete}

The validated framework is used to quantify the chloride diffusion in the micro and meso-scales for both the PCM incorporated and control cases. Figures 12(a) and (b) show the relative performance in terms of the ratio of the accelerated apparent diffusion coefficient $\left(D_{e}\right)$ to the initial diffusion coefficient $\left(D_{0}\right)$ for control and PCM-incorporated cases at micro and meso-scales respectively for the same duration of January 2018 in Providence, RI. Due to the similarity in stiffness degradation up to Day 8, the accelerated diffusion ratio is similar for both the cases. However, for the rest of the duration, PCM incorporated materials show a vastly improved chloride resistance. Overall, for both mortar (Figure 12(a)) and concrete (Figure 12(b)), the PCM incorporated composite shows a significant decrease in diffusion coefficient and superior chloride resistance as compared to control cases pointing to improved durability against freeze-thaw cycles when PCMs are incorporated. 



Figure 12. Relative ratios of accelerated apparent diffusion coefficient $\left(\mathrm{D}_{\mathrm{e}}\right)$ to initial diffusion coefficient $\left(\mathrm{D}_{0}\right)$ during January 2018 for (a) mortars and (b) concretes

The forthcoming section uses the accelerated diffusion behavior to obtain a comparative probabilistic failure analysis of PCM incorporated and control RC decks with time.

\subsection{Probabilistic modeling of lifetime distribution}

This section presents a probabilistic comparative analysis of the freeze-thaw and chloride diffusion-induced deterioration in RC bridge decks due to the vastly different chloride diffusive behavior shown by PCMincorporated concrete and control concrete. In RC structures such as a bridge deck, chloride ingress is often the cause of reinforcement corrosion which otherwise stays passive embedded in the alkaline concrete. Once the chloride concentration exceeds a threshold value at the surface of the reinforcement, it destroys the protective passive layer causing catastrophic degradation of the embedded reinforcement and thus its strength. Chloride ingress is accelerated due to material degradation that forms cracks on the surface. These provide an easy pathway for chloride diffusion across the concrete cover especially in frost deteriorated bridge decks. When deicing salts are applied on the surface of concrete decks, the chloride content $C(x, t)$ at a depth $x$ and time $t$ is can be defined as shown in Equation 11 [20].

$$
C(x, t)=C_{0}\left[1-\operatorname{erf}\left(\frac{x}{2 \sqrt{t D}}\right)\right]
$$

Where $C_{0}$ is the surface chloride content, $D$ is the apparent chloride diffusion coefficient and erf is the error function. This model is based on the observation that no chlorides accumulate with time [71]. The critical chloride concentration at the surface of the reinforcement is assumed to be $1 \mathrm{~kg} / \mathrm{m}^{3}$ and the concrete cover to be $50 \mathrm{~mm}$ [20]. The statistical parameter $C_{0}$ follows a lognormal distribution with a mean of $3.5 \mathrm{~kg} / \mathrm{m}^{3}$ and coefficient of variation 0.5 [20]. The apparent diffusion coefficient is characterized with time as shown in Equation 12 [72]. 


$$
D=D_{0} t^{\alpha}
$$

Where $D_{0}$ is taken to be $2 \times 10^{-12} \mathrm{~m}^{2} / \mathrm{s}$ [20] and the time coefficient $\alpha$ is determined from the variation of diffusion coefficient with time mentioned in Section 3.2 (Figure 12). The limit state function is bounded by the critical chloride concentration $C_{c r}$ as shown in Equation 13.

$$
g(x, t)=C_{c r}-C(x, t)
$$

The probability for chloride concentration at reinforcement to be less than the critical chloride reinforcement is computed following first order reliability method. This procedure involves definition of an appropriate limit state equation (here Equation 13 is used as limit state equation). A safety index $\beta$ governs the termination of the iterative procedure at a predetermined tolerance level (which is 0.001 [73] in this case). The iterative procedure proceeds with the computation of the random variable at every step as per Equation 14 [73].

$$
x_{i}^{*}=\mu_{X_{i}}^{N}-\alpha_{X_{i}} \beta \sigma_{X_{i}}^{N}
$$

Where $x_{i}^{*}$ is the design point (for $\mathrm{i}=1,2, \ldots \mathrm{n}$ ) for the non-normal variable; $\mu_{X_{i}}^{N}$ and $\sigma_{X_{i}}^{N}$ are the mean and standard deviation for the equivalent standard normal variable $X_{i} ; \alpha_{X_{i}}$ is the direction cosine at design point $x_{i}^{*}$ as shown in Equation 15.

$$
\alpha_{X_{i}}=\frac{\left(\frac{\partial g}{\partial X_{i}}\right) \sigma_{X_{i}}^{N}}{\sqrt{\sum_{i=1}^{n}\left(\frac{\partial g}{\partial X_{i}} \sigma_{X_{i}}^{N}\right)^{2}}}
$$

The probability of failure $P_{f}$ is obtained from $\beta$ as per Equation 16 .

$$
P_{f}=\varphi(-\beta)
$$

Where $\varphi$ is the normal cumulative distribution function defined for any variable $p$ in Equation 17 [73].

$$
\varphi(p)=\frac{1}{\sqrt{2 \pi}} \int_{-\infty}^{p} e^{-t^{2} / 2} d t
$$

The probabilistic model is implemented in a MATLAB $\odot$ script that incorporates a parametric variation of $\alpha$ which has a value of 0.41 for control concrete and 0.23 for PCM incorporated concrete as obtained from regression analysis by fitting the relationships shown in Figure 12(b) to Equation 12. The parameter $\alpha$ essentially captures the accelerated diffusion due to progressive freeze thaw damage in control and PCM incorporated concrete. Figure 13 reports the cumulative probability of failure for both control and PCMincorporated concrete bridge deck cases. As observed in Figure 13, the probability of failure due to chloride 
ingress in frost-damaged RC deck is significantly lower in case of PCM-incorporated concrete than control concrete and the efficiency increases progressively with increase in time. This comparative analysis depicts a conservative scenario where the same amounts of deicing salts are used for both cases. In a practical scenario, the lifetime of the PCM-incorporated RC structure will be significantly enhanced owing to a reduced frequency of deicing salt demand. The numerical approach followed in this study explains a holistic gain in durability of the structure resulting from the improved freeze-thaw resistance of PCM incorporated cementitious materials. The reduced number of freeze-thaw cycles helps to maintain the integrity of the structure which in turn enhances its chloride resistance over its life span.

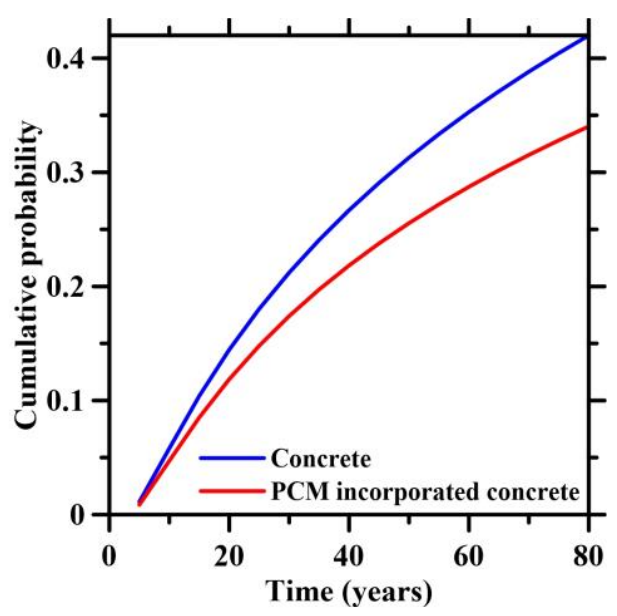

Figure 13. Cumulative probability distribution of failure due to chloride ingress in frost damaged RC deck

\section{CONCLUSIONS}

This paper presents a detailed evaluation of the effectiveness of microencapsulated PCM-incorporation in concrete bridge decks subjected to combined freeze-thaw and chloride ingress-induced deterioration. The evaluation is performed using a multiscale-numerical approach. A macro-scale bridge deck model predicts the surface temperature profiles for the month of January 2018 in Providence, RI based on solar radiation and ambient temperature. The model inputs effective material properties obtained by FE-based numerical homogenization of the inherent material properties of each component phases of the heterogeneous cementitious material at micro and meso scales establishing an efficient micro-macro relationship. A comparative analysis is drawn up between the control concrete and PCM-incorporated concrete with PCM replacing $20 \%$ of sand by volume. Consequently, the latent heat released by the PCMs reduces the number of freeze-thaw cycles as depicted by the surface temperature profile from the macroscale deck model. For the month of January 2018 in Providence, the PCM incorporated concrete shows a 70\% reduction in the number of freeze thaw cycles which establishes the potential of its application. To obtain a holistic picture of the benefits of improved freeze-thaw resistance of PCM modified concrete, a microstructure guided 
approach is implemented to characterize the frost-induced deterioration and resulting chloride ingress in both the mortars as well as concretes. A mortar-scale model captures the damage induced due to freezethaw cycles in the cement paste matrix using a progressive continuum damage model initiated by the volume expansion of the freezing pore solution. Hereafter, a mass diffusion model quantifies the diffusivity of chlorides in the degraded matrix using Fick's law of diffusion. The combined approach allows a detailed insight into the mutually dependent phenomena of freeze-thaw damage and chloride ingress. The reduced stiffness and accelerated diffusivity thus obtained in the mortar scale are scaled up to obtain the behavior of corresponding concretes. Finally, a comparison is depicted between the PCM-modified concrete and the control concrete in terms of the life of a RC deck subjected to freeze-thaw-induced damage and chloride ingress. Owing to the vastly reduced chloride ingress in the concrete cover of RC decks made from PCMincorporated concrete, a significant improvement in its survival probability is observed for PCMincorporated concrete deck as compared to control one. Thus the beneficial impact of PCM incorporation in concretes in terms of the frost-resistance advocates its use in concrete bridge decks. Moreover, the framework presented in the paper enables modification of material properties at different length scales for optimized performance of such durable concretes.

\section{ACKNOWLEDGMENTS}

The authors acknowledge the support from Department of Civil and Environmental Engineering (CVE) and College of Engineering (COE) at the University of Rhode Island (URI) towards this study.

\section{REFERENCES}

[1] D.P. Bentz, R. Turpin, Potential applications of phase change materials in concrete technology, Cement and Concrete Composites. 29 (2007) 527-532.

[2] P. Bamonte, A. Caverzan, N. Kalaba, M. Lamperti Tornaghi, Lightweight Concrete Containing Phase Change Materials (PCMs): A Numerical Investigation on the Thermal Behaviour of Cladding Panels, Buildings. 7 (2017) 35.

[3] T.-C. Ling, C.-S. Poon, Use of phase change materials for thermal energy storage in concrete: An overview, Construction and Building Materials. 46 (2013) 55-62.

[4] Y. Farnam, H.S. Esmaeeli, P.D. Zavattieri, J. Haddock, J. Weiss, Incorporating phase change materials in concrete pavement to melt snow and ice, Cement and Concrete Composites. 84 (2017) 134-145.

[5] A.M. Thiele, G. Sant, L. Pilon, Diurnal thermal analysis of microencapsulated PCM-concrete composite walls, Energy Conversion and Management. 93 (2015) 215-227.

[6] A.M. Thiele, A. Jamet, G. Sant, L. Pilon, Annual energy analysis of concrete containing phase change materials for building envelopes, Energy Conversion and Management. 103 (2015) 374-386.

[7] Y. Konuklu, M. Ostry, H.O. Paksoy, P. Charvat, Review on using microencapsulated phase change materials (PCM) in building applications, Energy and Buildings. 106 (2015) 134155 . 
[8] T. Khadiran, M.Z. Hussein, Z. Zainal, R. Rusli, Advanced energy storage materials for building applications and their thermal performance characterization: A review, Renewable and Sustainable Energy Reviews. 57 (2016) 916-928.

[9] A. Jayalath, P. Mendis, R. Gammampila, L. Aye, Applications of phase change materials in concrete for sustainable built environment: a review, Digital Library of University of Moratuwa Sri Lanka. (2013). http://dl.lib.mrt.ac.lk/handle/123/9349 (accessed May 25, 2018).

[10] A. Arora, G. Sant, N. Neithalath, Numerical simulations to quantify the influence of phase change materials (PCMs) on the early- and later-age thermal response of concrete pavements, Cement and Concrete Composites. 81 (2017) 11-24.

[11] B. Šavija, E. Schlangen, Use of phase change materials (PCMs) to mitigate early age thermal cracking in concrete: Theoretical considerations, Construction and Building Materials. 126 (2016) 332-344.

[12] F. Fernandes, S. Manari, M. Aguayo, K. Santos, T. Oey, Z. Wei, G. Falzone, N. Neithalath, G. Sant, On the feasibility of using phase change materials (PCMs) to mitigate thermal cracking in cementitious materials, Cement and Concrete Composites. 51 (2014) 14-26.

[13] H.S. Esmaeeli, Y. Farnam, D.P. Bentz, P.D. Zavattieri, W.J. Weiss, Numerical simulation of the freeze-thaw behavior of mortar containing deicing salt solution, Mater Struct. 50 (2017) 96.

[14] G.G. Litvan, Frost action in cement in the presence of De-Icers, Cement and Concrete Research. 6 (1976) 351-356.

[15] T.C. Powers, A Working Hypothesis for Further Studies of Frost Resistance of Concrete, JP. 41 (1945) 245-272.

[16] Li Wenting, Pour-Ghaz Mohammad, Castro Javier, Weiss Jason, Water Absorption and Critical Degree of Saturation Relating to Freeze-Thaw Damage in Concrete Pavement Joints, Journal of Materials in Civil Engineering. 24 (2012) 299-307.

[17] Y. Farnam, S. Dick, A. Wiese, J. Davis, D. Bentz, J. Weiss, The influence of calcium chloride deicing salt on phase changes and damage development in cementitious materials, Cement and Concrete Composites. 64 (2015) 1-15.

[18] Y. Farnam, A. Wiese, D. Bentz, J. Davis, J. Weiss, Damage development in cementitious materials exposed to magnesium chloride deicing salt, Construction and Building Materials. 93 (2015) 384-392.

[19] Y. Farnam, D. Bentz, A. Sakulich, D. Flynn, J. Weiss, Measuring Freeze and Thaw Damage in Mortars Containing Deicing Salt Using a Low-Temperature Longitudinal Guarded Comparative Calorimeter and Acoustic Emission, ACEM. 3 (2014) 316-337. doi:10.1520/ACEM20130095.

[20] M.G. Stewart, D.V. Rosowsky, Time-dependent reliability of deteriorating reinforced concrete bridge decks, Structural Safety. 20 (1998) 91-109.

[21] H.S. Esmaeeli, Y. Farnam, J.E. Haddock, P.D. Zavattieri, W.J. Weiss, Numerical analysis of the freeze-thaw performance of cementitious composites that contain phase change material (PCM), Materials \& Design. 145 (2018) 74-87.

[22] M. Koniorczyk, D. Gawin, B.A. Schrefler, Modeling evolution of frost damage in fully saturated porous materials exposed to variable hygro-thermal conditions, Computer Methods in Applied Mechanics and Engineering. 297 (2015) 38-61.

[23] P. Wriggers, S.O. Moftah, Mesoscale models for concrete: Homogenisation and damage behaviour, Finite Elements in Analysis and Design. 42 (2006) 623-636. 
[24] J. Mazars, A description of micro- and macroscale damage of concrete structures, Engineering Fracture Mechanics. 25 (1986) 729-737.

[25] J. Mazars, G. Pijaudier-Cabot, From damage to fracture mechanics and conversely: A combined approach, International Journal of Solids and Structures. 33 (1996) 3327-3342.

[26] F. Nilenius, F. Larsson, K. Lundgren, K. Runesson, Mesoscale modelling of crack-induced diffusivity in concrete, Comput Mech. 55 (2015) 359-370.

[27] P. Zhang, Y. Cong, M. Vogel, Z. Liu, H.S. Müller, Y. Zhu, T. Zhao, Steel reinforcement corrosion in concrete under combined actions: The role of freeze-thaw cycles, chloride ingress, and surface impregnation, Construction and Building Materials. 148 (2017) 113121.

[28] W. Jiang, X. Shen, J. Xia, L. Mao, J. Yang, Q. Liu, A numerical study on chloride diffusion in freeze-thaw affected concrete, Construction and Building Materials. 179 (2018) 553-565.

[29] S. Das, A. Maroli, N. Neithalath, Micromechanical Modeling for Material Design of Durable Infrastructural Materials: The Influence of Aggregate and Matrix Modification on Elastic Behavior of Mortars, International Conference on Durability of Concrete Structures. (2016).

[30] K. Mohsen, A.G. Straatman, A thermal periodic boundary condition for heating and cooling processes, International Journal of Heat and Fluid Flow. 28 (2007) 329-339.

[31] J. Sanahuja, C. Toulemonde, Numerical homogenization of concrete microstructures without explicit meshes, Cement and Concrete Research. 41 (2011) 1320-1329.

[32] O. van der Sluis, P.J.G. Schreurs, W.A.M. Brekelmans, H.E.H. Meijer, Overall behaviour of heterogeneous elastoviscoplastic materials: effect of microstructural modelling, Mechanics of Materials. 32 (2000) 449-462.

[33] H.A. Meier, E. Kuhl, P. Steinmann, A note on the generation of periodic granular microstructures based on grain size distributions, International Journal for Numerical and Analytical Methods in Geomechanics. 32 (2008) 509-522.

[34] B.D. Lubachevsky, F.H. Stillinger, E.N. Pinson, Disks vs. spheres: Contrasting properties of random packings, Journal of Statistical Physics. 64 (1991) 501-524.

[35] B.D. Lubachevsky, F.H. Stillinger, Geometric properties of random disk packings, Journal of Statistical Physics. 60 (1990) 561-583.

[36] B.D. Lubachevsky, How to simulate billiards and similar systems, Journal of Computational Physics. 94 (1991) 255-283.

[37] S. Nayak, S. Das, A microstructure-guided numerical approach to evaluate strain sensing and damage detection ability of random heterogeneous self-sensing structural materials, Computational Materials Science. 156 (2019) 195-205.

[38] S. Das, A. Maroli, S.S. Singh, T. Stannard, X. Xiao, N. Chawla, N. Neithalath, A microstructure-guided constitutive modeling approach for random heterogeneous materials: Application to structural binders, Computational Materials Science. 119 (2016) 52-64.

[39] S. Das, M. Aguayo, S.D. Rajan, G. Sant, N. Neithalath, Microstructure-guided numerical simulations to predict the thermal performance of a hierarchical cement-based composite material, Cement and Concrete Composites. 87 (2018) 20-28.

[40] S. Das, P. Yang, S.S. Singh, J.C.E. Mertens, X. Xiao, N. Chawla, N. Neithalath, Effective properties of a fly ash geopolymer: Synergistic application of X-ray synchrotron tomography, nanoindentation, and homogenization models, Cement and Concrete Research. 78 (2015) $252-262$.

[41] M. Aguayo, S. Das, A. Maroli, N. Kabay, J.C.E. Mertens, S.D. Rajan, G. Sant, N. Chawla, N. Neithalath, The influence of microencapsulated phase change material (PCM) 
characteristics on the microstructure and strength of cementitious composites: Experiments and finite element simulations, Cement and Concrete Composites. 73 (2016) 29-41.

[42] D. Lawrence, R. Page, Control of air content in concrete, Concrete Technology Today. 19 (1998).

[43] S. Minapoor, S. Ajeli, M.J. Toghchi, Simulation of Non-Crimp 3D Orthogonal Carbon Fabric Composite for Aerospace Applications Using Finite Element Method, 9 (2015) 9.

[44] Rubitherm GmbH,

https://www.rubitherm.eu/en/index.php/productcategory/mikroverkapselung (accessed March 28, 2019).

[45] M. Kheradmand, M. Azenha, J. Aguiar, J. Castro-Gomes, Experimental and numerical studies of hybrid PCM embedded in plastering mortar for enhanced thermal behaviour of buildings | Elsevier Enhanced Reader, Energy. 94 (2016) 250-261.

[46] Roberts-Wollman Carin L., Breen John E., Cawrse Jason, Measurements of Thermal Gradients and their Effects on Segmental Concrete Bridge, Journal of Bridge Engineering. 7 (2002) 166-174.

[47] Branco Fernando A., Mendes Pedro A., Thermal Actions for Concrete Bridge Design, Journal of Structural Engineering. 119 (1993) 2313-2331.

[48] National Oceanic and Atmospheric Administration, (2018). http://www.noaa.gov/ (accessed May 24, 2018).

[49] K. Riding, J. Poole, A. Schindler, Temperature Boundary Condition Models for Concrete Bridge Members, ACI Materials Journal. (2007) 379-387.

[50] ASTM Standard, C680-10, Standard practice for estimate of the heat gain or loss and the surface temperatures of insulated flat, cylindrical and spherical systems by use of computer programs, in: ASTM Standard, C680-10, Standard Practice for Estimate of the Heat Gain or Loss and the Surface Temperatures of Insulated Flat, Cylindrical and Spherical Systems by Use of Computer Programs, n.d.

[51] S. Nayak, N.M.A. Krishnan, S. Das, Microstructure-guided numerical simulation to evaluate the influence of phase change materials (PCMs) on the freeze-thaw response of concrete pavements, Construction and Building Materials. 201 (2019) 246-256.

[52] A. Saetta, R. Scotta, R. Vitaliani, Stress Analysis of Concrete Structures Subjected to Variable Thermal Loads, Journal of Structural Engineering. 121 (1995) 446-457.

[53] B. Zuber, J. Marchand, Modeling the deterioration of hydrated cement systems exposed to frost action: Part 1: Description of the mathematical model, Cement and Concrete Research. 30 (2000) 1929-1939.

[54] J.P. Ollivier, J.C. Maso, B. Bourdette, Interfacial transition zone in concrete, Advanced Cement Based Materials. 2 (1995) 30-38.

[55] D.P. Bentz, Influence of internal curing using lightweight aggregates on interfacial transition zone percolation and chloride ingress in mortars, Cement and Concrete Composites. 31 (2009) 285-289.

[56] F. Grondin, M. Matallah, How to consider the Interfacial Transition Zones in the finite element modelling of concrete?, Cement and Concrete Research. 58 (2014) 67-75.

[57] F. Gong, Y. Wang, D. Zhang, T. Ueda, Mesoscale Simulation of Deformation for Mortar and Concrete under Cyclic Freezing and Thawing Stress, ACT. 13 (2015) 291-304.

[58] G. Constantinides, F.-J. Ulm, The effect of two types of C-S-H on the elasticity of cementbased materials: Results from nanoindentation and micromechanical modeling, Cement and Concrete Research. 34 (2004) 67-80. 
[59] A. Neville, Properties of concrete, 1995.

[60] O. Coussy, P.J.M. Monteiro, Poroelastic model for concrete exposed to freezing temperatures, Cement and Concrete Research. 38 (2008) 40-48.

[61] J. Mazars, G. Pijaudier-Cabot, Continuum Damage Theory-Application to concrete, Journal of Engineering Mechanics. 115 (1989).

[62] M. Hain, P. Wriggers, Numerical homogenization of hardened cement paste, Comput Mech. 42 (2008) 197-212.

[63] M. Hasan, T. Ueda, Stress-Strain Relationship of Frost-Damaged Concrete Subjected to Fatigue Loading, | Journal of Materials in Civil Engineering. Vol 20, No 1 (2008). https://ascelibrary.org/doi/abs/10.1061/(ASCE)0899-1561(2008)20:1(37) (accessed June 2, 2018).

[64] K.A.T. Vu, M.G. Stewart, Structural reliability of concrete bridges including improved chloride-induced corrosion models, Structural Safety. 22 (2000) 313-333.

[65] M.K. Kassir, M. Ghosn, Chloride-induced corrosion of reinforced concrete bridge decks, Cement and Concrete Research. 32 (2002) 139-143.

[66] J. Broomfield, Corrosion of steel in concrete: understanding, investigation and repair, Taylor \& Francis, 2003.

[67] T. Wu, P. Wriggers, Multiscale diffusion-thermal-mechanical cohesive zone model for concrete, Computational Mechanics. 55 (2015) 999-1016.

[68] J.-J. Zheng, X.-Z. Zhou, Y.-F. Wu, X.-Y. Jin, A numerical method for the chloride diffusivity in concrete with aggregate shape effect, Construction and Building Materials. 31 (2012) 151156.

[69] Q. Liu, J. Xia, D. Easterbrook, J. Yang, L. Li, Three-phase modelling of electrochemical chloride removal from corroded steel-reinforced concrete, Construction and Building Materials. 70 (2014) 410-427.

[70] M. Collepardi, A. Marcialis, R. Turriziani, Penetration of Chloride Ions into Cement Pastes and Concretes, Journal of the American Ceramic Society. 55 (1972) 534-535.

[71] P. Hoffman, R. Weyers, Predicting critical chloride levels in concrete bridge decks, in: Rotterdam, 1994: pp. 957-959.

[72] H.-W. Song, C.-H. Lee, K.Y. Ann, Factors influencing chloride transport in concrete structures exposed to marine environments, Cement and Concrete Composites. 30 (2008) $113-121$.

[73] A. Haldar, S. Mahadevan, Probability, reliability, and statistical methods in engineering design, John Wiley, 2000. 